\title{
UMA PROPOSTA DE ATIVIDADE PARA O ENSINO DOS NÚMEROS NA EDUCAÇÃO INFANTIL
}

\author{
Joanna Viero Wollmann'; Jociléia Scherer ${ }^{2}$, Luís Sebastião Barbosa Bemme ${ }^{3}$
}

\section{RESUMO}

Esta comunicação tem como objetivo apresentar uma proposta de atividade voltada para o ensino de números na Educação Infantil. Tal atividade foi elaborada a partir das ações desenvolvidas na disciplina de Ensino de Matemática I do Curso de Pedagogia. Este estudo é de caráter qualitativo sendo considerado um estudo descritivo. Resalta-se o papel do lúdico na construção da atividade e espera-se que a partir dessa ação a criança vá se apropriando o conceito de número que é fundamental para a construção conceitual da Matemática.

Palavras-chave: Ensino de Matemática. Pedagogia. Infância.

\section{Eixo Temático: Educação, Cultura e Comunicação - ECC}

\section{INTRODUÇÃO}

Esta comunicação tem por objetivo apresentar uma proposta de atividade voltada para o ensino de números na Educação Infantil. Tal ação justifica-se na medida em que a Matemática é entendida como um elemento cultural construído ao longo da História da humanidade.

Nesse sentido é essencial para o sujeito conhecer a cultura que o cerca, para poder apoderar-se dos instrumentos simbólicos e com isso, atuar, criar e intervir na sociedade. A Matemática, nesse contexto, se torna uma ferramenta criada pelo homem para satisfazer as necessidades instrumentais e integrativas (MOURA, 2011). Sublinha-se a necessidade de ações que favoreçam a apropriação de ideias e conceitos matemáticos desde o momento em que a criança se insere no espaço escolar, uma vez que,

\footnotetext{
1 Universidade Franciscana- UFN joanna.viero@ufn.edu.br

2 Universidade Franciscana- UFN jocileia.scherer@ufn.edu.br

3 Prof. Doutor em Ensino de Ciências e Matemática
} 
Se a Matemática é parte do mundo da criança, devemos fazer com que a criança aprenda este conhecimento como parte do seu equipamento cultural, para que possa intervir com instrumentos capazes de auxiliá-la na construção da sua vida. (MOURA, p.26, 2011).

Virgulino (2014) salienta que o ensino de Matemática na Educação Infantil deve atender as necessidades próprias da criança para construir seus conhecimentos incidindo nos mais variados domínios do pensamentos além de considerar as necessidades sociais para melhore instrumentalizá-las para viver, participar e compreender um mundo que exige diferentes conhecimentos a habilidades.

O professor, segundo Fonseca (1997), tem um papel fundamental ao planejar a sua intervenção, já que esta precisa estar de acordo com o etapa de desenvolvimento do sujeito e deve favorecer o raciocínio lógico do aluno desde o momento em que inicia sua trajetória escolar.

No entanto, é necessário compreender os processos pelos quais a criança aprende. Nesta comunicação defende-se a ideia da utilização de atividades lúdicas como fonte geradora da aprendizagem na Educação Infantil.

A palavra lúdico, de acordo com Huizinga (2019), surge do latim ludus, que significa brincar. Este conceito refere-se à ligação entre o lúdico e a criança, sinalizando para análise da importância do lúdico em todo desenvolvimento da criança, caracterizando, consequentemente, a sua aprendizagem.

Para Dias (2013) as atividades lúdicas são fundamentais para a interação da criança com o meio, sendo através do lúdico que a criança inicia o processo de desenvolvimento da imaginação, abstração e a aplicação de ações relacionadas ao mundo real.

As atividades lúdicas contemplam não somente as brincadeiras, mas também jogos, atividades artísticas e musicais, e a contação de histórias. Assim, o processo lúdico de aprendizagem deve ser prazeroso, respeitando a individualidade de cada criança, de maneira que elas possam demonstrar suas emoções, propiciando as interações sociais. Segundo Friedmann (1992, p.26), as brincadeiras fazem parte do patrimônio lúdico-cultural, traduzindo valores, costumes, formas de pensamento e ensinamentos. 
Salienta-se que a ludicidade na educação pode se tornar uma ferramenta rica, não só na contação de história, mas pode ser utilizada para diversas propostas pedagógicas. Provocados por essas questões, na sequência apresenta-se os procedimentos metodológicos deste estudo.

\section{METODOLOGIA}

Esta comunicação fundamenta-se na pesquisa qualitativa de cunho descritivo. Para Gerhardt e Silveira (2009) na pesquisa qualitativa, o cientista é o sujeito e o objeto de suas pesquisas, sendo que esta não se preocupa com aspectos da realidade que não podem ser quantificados, baseando-se na compreensão e explicação da dinâmica das relações sociais.

Já a pesquisa de cunho descritivo exige do investigador uma série de informações sobre o que deseja pesquisar. Esse tipo de estudo pretende descrever os fatos e fenômenos de determinada realidade. (TRIVIÑOS, 1987).

A proposta de atividade de ensino apresentada é resultado das discussões teóricos e estudos conceituais, realizados na disciplina de Ensino de Matemática I do curso de Pedagogia de uma Universidade Comunitária do interior do Rio Grande do Sul, no segundo semestre de 2020.

\section{RESULTADOS E DISCUSSÕES}

Nesse item do texto apresentamos os resultados e discussões. Para essa comunicação entedemos que os resultados é a proposta de atividade que foi construída na disciplina de Ensino de Matemática I do curso de Pedagogia, já nas discussões pontuamos aspectos que podem ser desenvolvidos com a mesma, uma vez que a atividade ainda não foi desenvolvida.

\subsection{Atividade de Ensino}

A atividade proposta é baseada na letra da música " $A$ galinha do vizinho" que faz parte do livro "Folclore Brasileiro", da Turma da Mônica. Tal proposta foi pensada 


\section{QUFN}

com o intuito de desenvolver uma atividade lúdica com as crianças da Educação Infantil. A atividade foi planejada para ser desenvolvida em cinco momentos como indicado no Esquema 01.

Esquema 01. Momentos da Atividade.

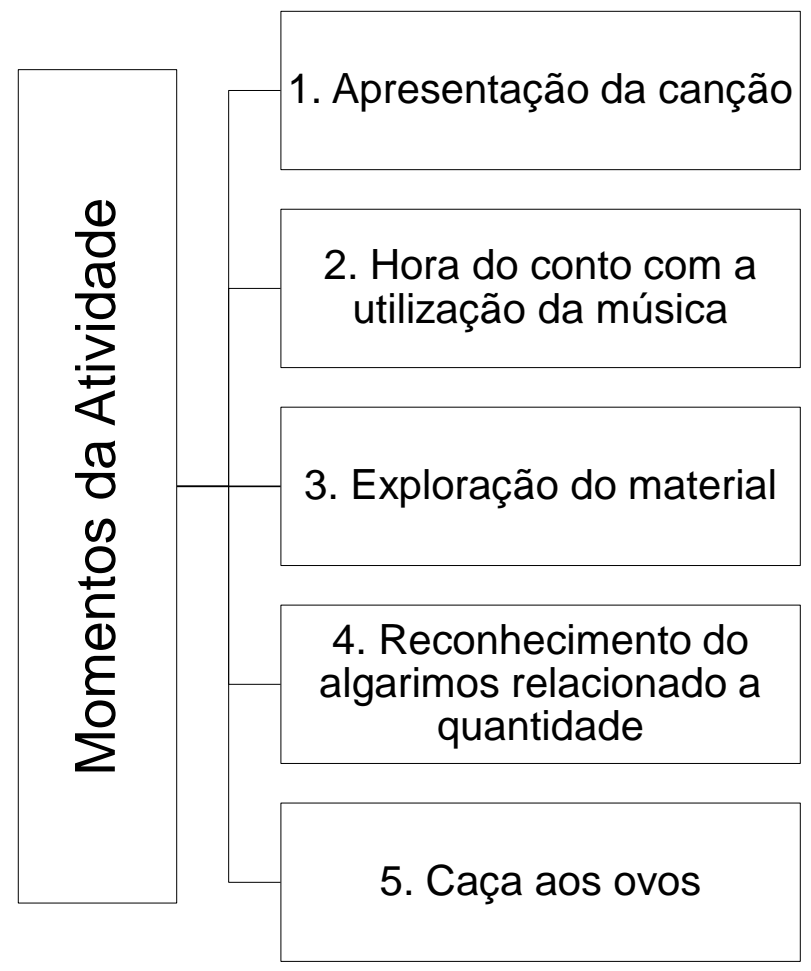

Fonte: Organização dos autores.

No primeiro momento, o professor irá apresenta a canção aos alunos, questionando se os mesmos já conhecem, se sabem cantar ou ainda se já viram uma galinha e como ela é, também poderá questionar sobre as funções e utilidades do ovo na nossa alimentação. Para isso o professor irá dispor de um cartaz com a letra da música e a ilustração como indicado na Figura 1. 


\section{QUFN}

Imagem 01. Ilustração com a cantiga "A galinha do vizinho".

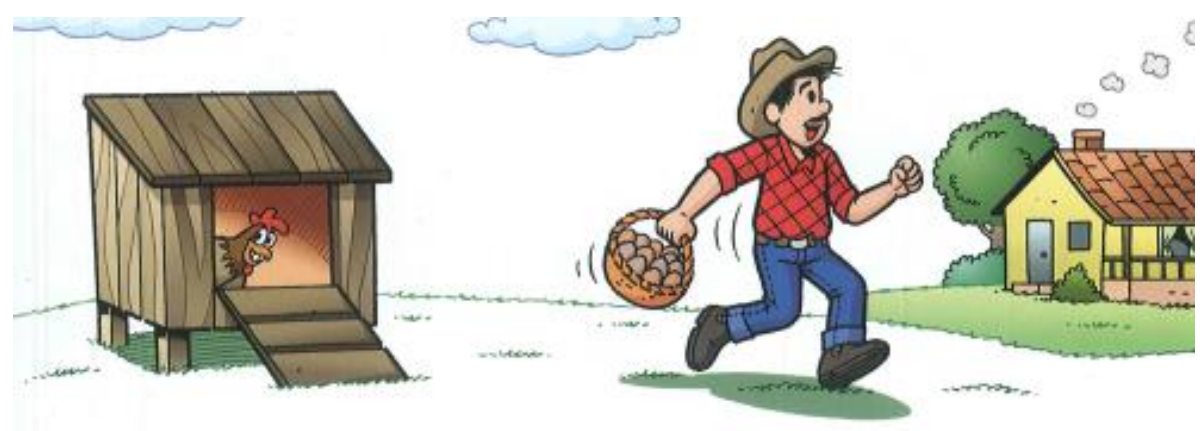

\section{A galinha Do vizinho}

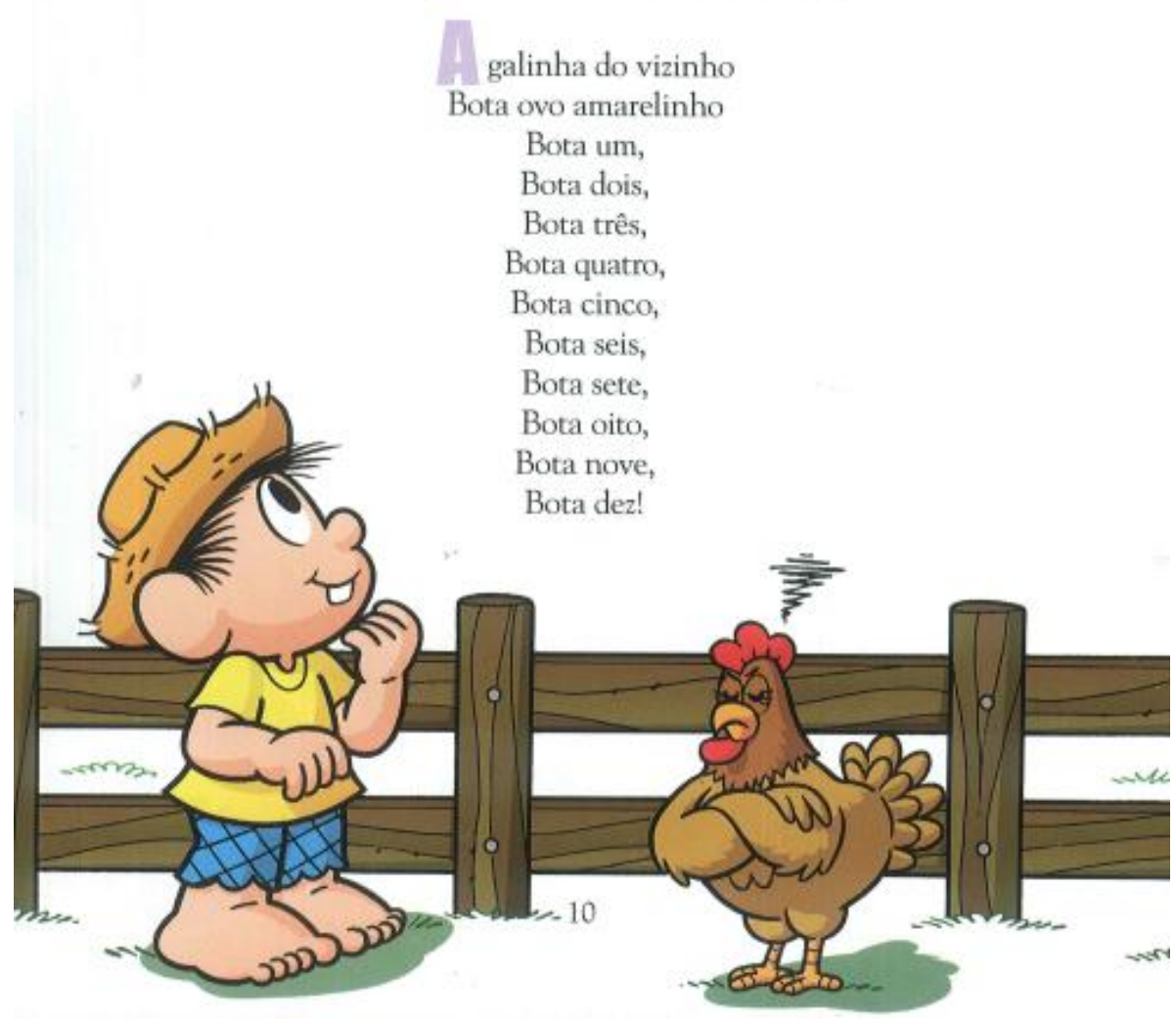

Fonte: (Sousa, 2009)

Embora, nessa etapa da escolarização, o foco não esteja na alfabetização, é importante que a criança entre em contato com a cultura escrita, e portanto, a necessidade da apresentação do material com a letra da música escrita.

No segundo momento o professor irá realizar a hora do conto utilizando a canção, inicialmente o professor irá cantar sozinho e depois convidará os alunos para que cantem junto. 
A medida em que a música é cantada, o professor irá utilizar a galinha feita de feltro juntamente os ovos e algarismos (Imagem 2) para ir ilustrando a canção. Conforme a docente for cantando a música, ela irá colocando os ovos e o algarismo correspondente na galinha.

Imagem 2 - Material manipulável.
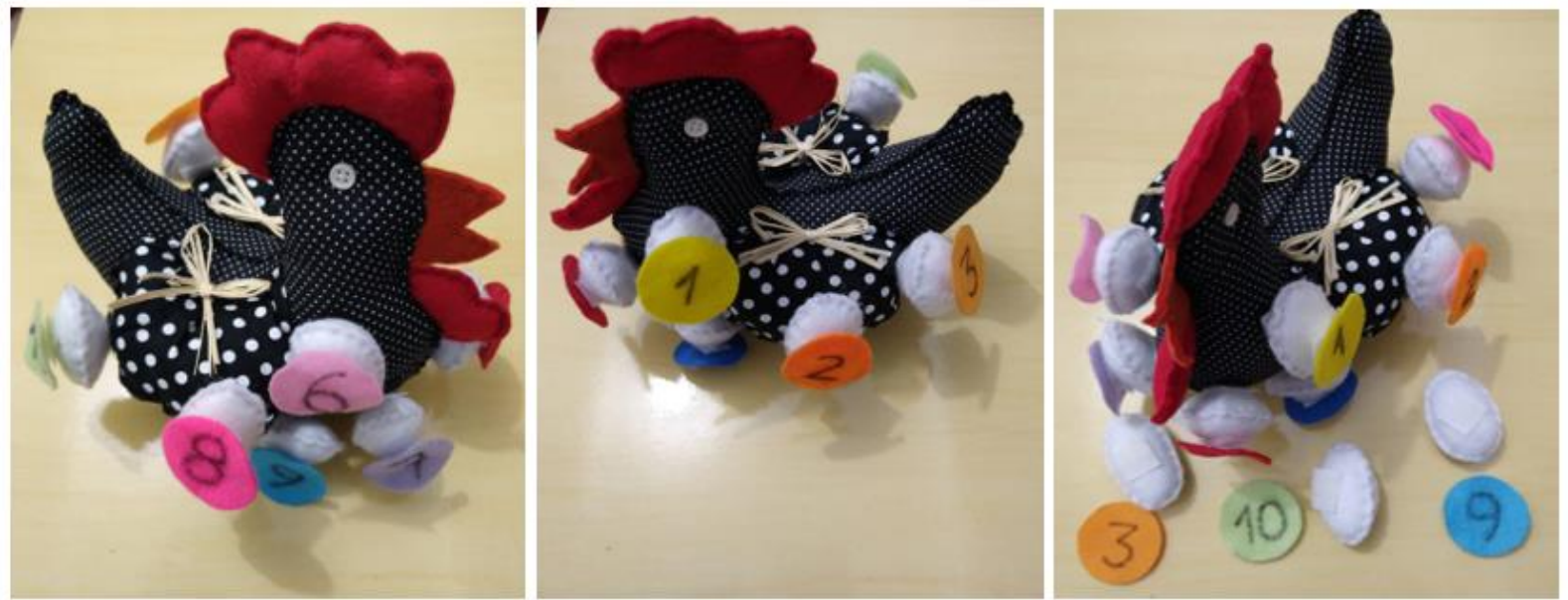

Fonte: Arquivo pessoal.

No terceiro momento da atividade haverá um rodízio do material concreto, cada aluno que desejar, pode assumir o papel do professor de ir colocando os ovos e o algarismo correspondente na galinha na medida em que os demais cantam.

O quarto momento a professora poderá, utilizando o material concreto, fazer alguns questionamentos para os alunos, levando os mesmos a relacionarem a quantidade com o algarimos. Por exemplo: "João", coloque quatro ovos na galinha e mostre o algarismo quatro.

No quinto e último momento será realizado uma atividade intitulado "Caça aos ovos". A professora irá distribuir ovos confeccionados em feltro pelo pátio da escola e os alunos terão que fazer uma busca. No final será feito a contagem do número de ovos que cada aluno encontrou.

\subsection{Resultados esperados}




\section{QPUFN}

Espera-se com essa atividade, a concretização da proposta pedagógica, elaborada de forma diversificada para a Educação Infantil, já que, nesse momento de escolarização, é fundamental o ensino baseado no lúdico e no concreto.

Moura (2011), relata que a consciência de que os sujeitos, ao aprenderem, não o fazem apenas como assimiladores de conhecimento. No processo de aprendizagem certos componentes internos não podem ser ignorados pelos educadores. A ideia de um indivíduo fácil de moldar e dirigir, a partir do seu exterior, foi substituída pela ideia de um sujeito que seleciona, assimila, interpreta, processa e confere significados aos seus estímulos.

Portanto, objetiva-se com essa atividade, obter um resultado satisfatório, onde tal proposta sirva como estímulo de vários desencadenadores de saberes para a criança, auxiliando o professor em sua análise pedagógica, no processo de desenvolvimento de cada discente, colaborando, neste sentido, com o seu trabalho na construção do saber.

Em vista disso, Vygotsky (1987, p. 35), salienta que [...] "o brincar é uma atividade humana criadora, na qual imaginação, fantasia e realidade interagem na produção de novas possibilidades de interpretação, de expressão e de ação pelas crianças [...]". A brincadeira faz parte do cotidiano das crianças.

Isto complementa o argumento de que a criança precisa de ludicidade em seu contexto escolar, pois se o brincar, o brinquedo e a brincadeira fazem parte da infância, a escola também precisa se organizar, no sentido de ser um lugar que permita que as crianças continuem brincando, de maneira que, por meio do lúdico, a instituição escolar amplie as aprendizagens, como um todo.

Ainda de acordo com Antunes (2014), a criança que brinca desenvolve sua linguagem oral, seu pensamento associativo, habilidades auditivas e sociais, construindo conceitos de relações espaciais, apropriando-se de relações de conservação, seriação, classificação e aptidões visuoespaciais.

\section{CONCLUSÃO}


Esta comunicação tem como objetivo apresentar uma proposta de atividade voltada para o ensino de números na Educação Infantil. A partir desta atividade objetiva-se que as crianças, de forma lúdica, comecem a estabelecer a relação entre quantidade e algarismo.

Ressalta-se que o papel do docente é de ouvinte, observador e mediador, sendo que ele deve entender as situações de aprendizagem de cada criança, tornando-se envolvido com a exploração por parte dos seus alunos. Com isso é importante que o aluno sinta-se seguro para compartilhar suas situações com o educador.

No processo de ensino e aprendizagem o discente precisa do amparo do professor, de modo que ele se sinta seguro em relação ao desenvolvimento de determinadas atividades, e o educador deve ser flexível nas etapas do desenvolvimento da criança.

Neste sentido a atividade "A galinha do vizinho" tem potencial para se converter em uma atividade introdutória sobre a relação entre quantidade e algarismo na Educação Infantil.

\section{REFERÊNCIAS}

ANTUNES, Celso. O jogo e a Educação Infantil: falar e dizer/olhar e ver/escutar e ouvir. 9 ed. Petrópolis, RJ: Vozes, 2014.

DIAS, Elaine. A importância do lúdico no processo de ensino-aprendizagem na educação infantil. Revista Educação e Linguagem. p. 2 - 17.Vol. 7, nำ1. 2013.

FONSECA, S. Metodologia do Ensino da Matemática. Belo Horizonte, MG: Lê, 1997.

FRIEDMANN, Adriana. A evolução do brincar. In: FRIEDMANN, Adriana et al. In: O direito de brincar. São Paulo: Scritta: ABRINQ, 1992.

GERHARDT, Tatiana E; SILVEIRA, Denise T. Métodos de pesquisa. Porto Alegre: UFRGS, 2009. 
HUIZINGA, Johan. Homo Ludens: o jogo como elemento da cultura. 9ª ed. São Paulo: Perspectiva, 2019.

MOURA, Ariosvaldo de. A séria busca do jogo: do lúdico na Matemática. In:

KISHIMOTO, Tizuko M (Org). Jogo, brinquedo, brincadeira e a educação. 14 ed. São Paulo: Cortez, 2011.

SOUZA, Maurício de. Turma da Mônica: Folclore Brasileiro. Barueri, São Paulo: Girassol, 2009.

TRIVIÑOS, A.N.S. Introdução a pesquisa em Ciências Sociais: a pesquisa qualitativa em educação. São Paulo: Atlas, 1987.

VIRGULINO, Carina Silvana. O ensino da matemática na educação infantil. Disponível em: .Acesso em: 14 set. de 2021.

VYGOTSKY, L. S. A formação social da mente. São Paulo: Martins Fontes, 1987. 